UDK 616-008

\title{
WORKING CONDITIONS AS OCCUPATIONAL RISK FACTORS FOR FUNCTIONAL DISORDERS IN AGRICULTURE MACHINE OPERATORS
}

\author{
T.A. Novikova, S.S. Raykin, E.S. Buyanov, V.F. Spirin, R.B. Rakhimov
}

Federal Budget Institution of Science "Saratov Scientific Research Institute of Agricultural Hygiene" of Rospotrebnadzor, Russian Federation, Saratov region, Saratov, Zarechnaya St., 1a, 410022

\begin{abstract}
The complex physiological-hygienic evaluation of the working conditions of agricultural machine operators in the dynamics of the annual production cycle of growing crops is carried out. It is set that the machine operators performing basic types of work are subject to the combined effect of harmful factors of environment and labor process, the levels of which correspond by the degree of deviation from the hygienic standards to harmful labor conditions of 1-4 degrees (classes 3.1-3.4). Levels of blood pressure, hemodynamic and functional status (IFS) show tension of regulator systems and reducing of the body's adaptive capabilities of the machine operators that can be caused by exposure to adverse working conditions.

Key words: agriculture machine operators, working conditions on the tractors and combine harvesters, functional disorders, tension of adaptation mechanisms.
\end{abstract}

Tractor operators and machine operators (hereafter - agricultural operators) that work with agricultural equipment expose themselves to various professional health risks. They include higher levels of noise and vibration created by equipment operation, dust (organic and mineral), exhaust fumes, microclimatic discomfort in the cab, physical and emotional loads [1]. The impact of hazardous working conditions can lead to functional disorders and dysfunction of organs and systems of agricultural operators, malfunction of adaptive mechanisms, development of preclinical and pathological changes that advance profession-related and professional diseases $[3]$.

For this reason, determining the risk factors that decrease the body functional reserves will help develop and implement timely measures to maintain the health of agricultural operators which is the biggest professional group of agricultural employees.

The purpose of the study is to assess the working conditions and their impact on the functional condition of the agricultural operators.

\footnotetext{
${ }^{\circledR}$ Novikova T.A., Raykin S.S., Buyanov E.S., Spirin V.F., Rakhimov R.B., 2014

Novikova Tamara Anatolievna - Candidate of Biological Sciences, Associate professor, Head of Occupational medicine department (e-mail: Novikova_TA@niisgrospotrebnadzor.ru; ph./fax: +7 (845-2) 92-34-94.

Raykin Sergey Sergeevich - Junior research assistant (e-mail: Rser3001@yandex.ru; ph.: +7 (845-2) 92-34-94).

Buyanov Evgeny Sergeevich - Candidate of Medical Sciences, Head of Laboratory for ergonomics and occupational physiology in agriculture (e-mail: iisg@rospotrebnadzor.ru; ph.: +7 (845-2) 92-30-48).

Spirin Vladimir Fedorovich - MD, Professor, Director (e-mail: iisg@rospotrebnadzor.ru; ph.: +7 (845-2) 92-78-90).

Rakhimov Rustem Bakhrumovich - Acting junior research assistant of occupational medicine department (e-mail: iisg@rospotrebnadzor.ru; ph.: +7 (845-2) 92-78-90).
} 
Materials and methods. The hygienic studies included the measurement and hygienic assessment of the microclimate, noise and vibration, pollution of the working area, aerosols of predominantly fibrogenic action (APFA) and hazardous chemical pollutants, hard and intensive labor when operating a tractor or grain harvester, the most common equipment in the agricultural fleet of tractors. The study of the working conditions was conducted with the use of common hygienic methods and equipment when performing the main seasonal field works during the annual production cycles (harrowing, grubbing, grain seeding, and grain harvesting) at the farms in Saratov region that specialize in grain production.

The physiological studies were conducted in a group of 96 male operators in the field before the shift. The average age was $42.5 \pm 11.5$ years, the average length of service in the profession - 22.9 \pm 11.1 years. Among the examined, those with a length of service in the profession of under 10 years totaled $15.6 \%$, from 11 to 20 years $-30.2 \%$, from 21 to 30 years $31.3 \$$, and more than 30 years of service $-22.9 \%$.

The anthropometric indices were studied including height, weight, body mass index (BMI). With the help of the Korotkov sound method, we measured the heart rate (HR), systolic and diastolic arterial blood pressure (SBP and DBP, respectively). To measure the blood pressure, we used the classification of the Joint National Committee of the European Society of Hypertension (JNC-7-2003), in which the values of 120-129 / 80-84 mmHg constitute the optimal pressure, 130-139 / 85-89 mmHg - high normal pressure, over 139/89 - mmHg hypertension. We assessed the calculated hemodynamics indicators - pulse pressure (PP), normal is $30-50 \mathrm{~mm} \mathrm{Hg}$, the average dynamic pressure (ADP), which normally ranges from 75 to $85 \mathrm{mmHg}$, minute volume of blood (MVB) that in healthy people equals $4-8 \mathrm{l} / \mathrm{min}$, and total peripheral vascular resistance movement of blood (TPR) which normally can be in the range of 1,400 to 2,500 dynes. We calculated the cardiovascular endurance coefficient (EC), the increase in which indicates a weaker heart function, and decrease - a stronger heart function (normally EC equals 12-16).

To assess the heart condition, we used a computer heart screening system "Cardiovisor 06s", based on the method of disperse mapping electrocardiogram (DM ECG). The DM ECG method uses a standard ECS-signal only as a source of low-amplitude microvibrations of the surface potentials. The result of the computer processing of the ECG signal is not a set of conventional ECG-signs, but the map of dispersion changes in the myocardium. The "Myocardium" indicator of the computer screening system is a relative characteristic which characterizes the total amount of dispersion abnormalities of low-amplitude vibrations of ECG 
signal varying in the range from 0 to $100 \%$ and serving as the main marker of clinical interpretation of screening conclusion. The higher the value of the indicator, the more significant deviation from the norm.

We used the adaptive potential of the circulatory system (R.M. Baevsky, 2004) assessed by the index of functional changes (IFC) as an indicator that integrally reflects the function condition of the body; the indicator was used to determine the adaptation level, and functional body reserves. When assessing the results, the level of the functional condition was assessed at IFC $<2.59$ as sufficient functional capabilities, satisfactory adaptation; from 2.6 to $3.09-$ function tension, from 3.10 to 3.49 - weakening of functional capabilities, unsatisfactory adaptation; and $>3.5$ - sharp decrease in functional capabilities, adaptation collapse [2].

Statistical processing of the study results was carried out using electronic tables by Microsoft and Statistica 10. We calculated the arithmetical mean (M) and standard deviation (SD). The statistical significance of the test values in the subgroups was determined using Mann-Whitney U-test. The differences were considered statistically significant at $\mathrm{p}<0.05$.

Results and discussion. It was determined that during the entire annual production cycle, agricultural operators are exposed to a series of hazardous production and labor factors. Their deviation from the current hygienic standards matched with hazardous working conditions of the $1^{\text {st }}-4^{\text {th }}$ level (classes $3.1-3.4$ ) depending on the type of work and the operated machines (Table $1)$.

The cabs of the tractors and grain harvesters of older Russian models which do not have ACs or are equipped with ineffective fans - those currently constitute the majority (up to $80 \%$ ) of the agricultural fleet of vehicles - have an uncomfortable heated microclimate with the temperature exceeding the norm by $1-5.5^{\circ} \mathrm{C}$ which indicated hazardous labor conditions of the $1^{\text {st }}-4^{\text {th }}$ level (classes $3.1-3.4$ ). The thermal load level of the environment (TL-index) reached 28.9-30.0 ${ }^{\circ} \mathrm{C}$ which is considered hazardous labor conditions of the $4^{\text {th }}$ level (class 3.4). At the same time, with the help of working ACs in the cabs of tractors of harvesters of newer models RSM 101 «Vector» and RSM 142 «Akros», foreign manufactured tractors, for example, Class «Aksion», the temperature of the cab environment was in compliance with the hygienic standards (class 2). 
Table 1

Hygienic assessment of the labor conditions of agricultural operators during various periods of the production cycle

\begin{tabular}{|c|c|c|c|c|c|c|c|c|}
\hline \multirow{3}{*}{$\begin{array}{l}\text { Type of works } \\
\text { during the annual } \\
\text { production cycle }\end{array}$} & \multicolumn{6}{|c|}{$\begin{array}{l}\text { Assessment of labor factors } \\
\text { (class, hazard level) }\end{array}$} & \multicolumn{2}{|c|}{ Labor factors } \\
\hline & \multirow{2}{*}{$\begin{array}{l}\text { Hazardous } \\
\text { substances }\end{array}$} & \multirow[b]{2}{*}{ Microclimate } & \multirow[b]{2}{*}{ APFA } & \multirow[b]{2}{*}{ Noise } & \multicolumn{2}{|c|}{ Vibration } & \multirow[b]{2}{*}{ Difficulty } & \multirow[b]{2}{*}{ Intensity } \\
\hline & & & & & general & local & & \\
\hline \multirow{2}{*}{$\begin{array}{l}\text { Harrowing and } \\
\text { cultivation }\end{array}$} & $\underline{2}$ & $\underline{3.1}$ & 3.1-3.2 & $3.2-3.3$ & $\underline{3.2}$ & $\underline{3.2}$ & 3.2 & $\underline{3.2}$ \\
\hline & $\overline{2}$ & $\overline{2}$ & $\overline{2-3.1}$ & $\overline{3-1-3.2}$ & $\overline{2}$ & $\overline{2}$ & $\overline{3.1}$ & $\overline{3.2}$ \\
\hline \multirow{2}{*}{ Grain seeding } & $\underline{2}$ & $3.1-3.2$ & $\underline{3.2-3.4}$ & $\underline{3.2-3.2}$ & 3.1 & 3.2 & 3.2 & 3.2 \\
\hline & $\overline{2}$ & $2-3.1$ & $2-3.1$ & 3.1 & 2 & 2 & $\overline{3.1}$ & $\overline{3.2}$ \\
\hline \multirow{2}{*}{ Plowing (summer) } & $\underline{2}$ & $3.1-3.4$ & $\underline{3.1-3.2}$ & $\underline{3.2}$ & 3.1 & $\underline{3.1}$ & 3.2 & 3.2 \\
\hline & 2 & $2-3.1$ & $2-3.1$ & $3.1-3.2$ & 2 & 2 & $\overline{3.1}$ & $\overline{3.2}$ \\
\hline \multirow{2}{*}{ Grain harvesting } & 2 & $3.1-3.4$ & $\underline{3.1-3.3}$ & $3.1-3.2$ & 3.1 & 3.1 & $\underline{3.2}$ & 3.2 \\
\hline & 2 & $2-3.1$ & $2-3.1$ & $2-3.1$ & 2 & 2 & 3.1 & $\overline{3.2}$ \\
\hline
\end{tabular}

N o t e : $*$ - numerator - in the older models, denominator - recent and foreign models.

Air pollution included diesel internal combustion engine exhaust - a gas mixture (carbon oxide, nitrogen oxide, aldehydes, sulfur dioxide) which is continuously present in the breathing area in concentrations that do not exceed the maximum allowable levels.

Noise and vibration are among the unfavorable labor conditions of tractor and harvester operators. Broadband noise exceeds the maximum allowable levels in terms of low and high frequencies by up to $14.8 \mathrm{dBA}$. Equivalent noise level exceeded MAL by 1-17 dBA in all models and brands of the examined tractors when performing all types of field works. Elevated levels of general vibration at the workplace of the operators were revealed in tractors of older models (DG-75, T-4A) at the frequency of 2-4 hz, and the MAL excess averaged 1-7 $\mathrm{dB}$. In terms of vibration resistance, labor conditions were assessed as hazardous, $1^{\text {st }}-3^{\text {rd }}$ level (classes $3.1-3.3)$.

Labor difficulty when operating agricultural equipment is formed due to dynamic and static physical loads, and uncomfortable working posture. Labor intensity is determined by emotional and nervous intensity due to higher level of responsibility for the final result, tight field works schedule, and unbalanced work management. By the hygienic criteria R 2.2.2006-05, they were assessed as hazardous of the $1^{\text {st }}$ and $2^{\text {nd }}$ level (classes $3.1-3.2$ ).

The study results that describe the functional condition of the cardiovascular system of the operators are presented in Table 2 below. 
Indicators of the functional condition of the cardiovascular system of the agricultural operators $(M \pm S D)$

\begin{tabular}{|c|c|c|c|c|c|}
\hline \multirow{2}{*}{ Indicator } & \multirow{2}{*}{ Entire group } & \multicolumn{5}{|c|}{ Length of service in the profession, years } \\
\cline { 3 - 6 } & & $3-10$ & $11-20$ & $21-30$ & болеe 30 \\
\hline SBP & $143,0 \pm$ & $144,1 \pm$ & $132,9 \pm$ & $139,5 \pm$ & $151,4 \pm$ \\
(mmHg) & $18,2 \uparrow$ & $13,6^{*} \uparrow$ & 8,9 & 13,5 & $22,5^{*} \uparrow$ \\
\hline DBP & $86,0 \pm$ & $87,8 \pm$ & $79,3 \pm$ & $86,4 \pm$ & $87,8 \pm$ \\
(mmHg) & 13,3 & $15,5^{*}$ & 8,0 & $11,1^{*}$ & $7,6^{*}$ \\
\hline HR & $75,9 \pm$ & $76,2 \pm$ & $73,3 \pm$ & $72,8 \pm$ & $74,9 \pm$ \\
(beats/min) & 11,9 & 11,8 & 11,4 & 10,1 & 13,0 \\
\hline EC & $13,879 \pm$ & $14,067 \pm$ & $13,708 \pm$ & $14,142 \pm$ & $12,886 \pm$ \\
(st. lev.) & 3,6 & 2,9 & 2,7 & 3,2 & 5,2 \\
\hline PP & $56,9 \pm$ & $56,4 \pm$ & $53,6 \pm$ & $53,0 \pm$ & $63,6 \pm$ \\
(mmHg) & $12,7 \uparrow$ & $12,0 \uparrow$ & $8,7 \uparrow$ & $8,8 \uparrow$ & $20,7 \uparrow$ \\
\hline ADP & $105,0 \pm$ & $106,6 \pm$ & $97,1 \pm$ & $104,1 \pm$ & $109,0 \pm$ \\
(mmHg) & $13,8 \uparrow$ & $13,8^{*} \uparrow$ & $7,2 \uparrow$ & $11,2^{*} \uparrow$ & $10,6^{*} \uparrow$ \\
\hline MBV & $3505,3 \pm$ & $4043,4 \pm$ & $3789,6 \pm$ & $3137,1 \pm$ & $3000,4 \pm$ \\
(ml/min) & $1070,1 \downarrow$ & 1197,3 & $912,3 \downarrow$ & $829,3 \downarrow$ & $856,8^{*} \downarrow$ \\
\hline TPR & $2698,2 \pm$ & $2267,5 \pm$ & $2160,5 \pm$ & $2907,7 \pm$ & $3077,3 \pm$ \\
(dynes) & $1195,6 \uparrow$ & 706,4 & 613,0 & $1101,5^{*} \uparrow$ & $721,8^{*} \uparrow$ \\
\hline
\end{tabular}

Note : *-differences are significant as compared to group $2 ; \uparrow-\downarrow$ indicator values are higher and lower than the norm.

The data above shows that the mean group value (MGV) in the examined group exceeded the norm which may be considered an unfavorable symptom that indicates a disturbance in the compensation-adaptation abilities of the cardiovascular system and risks of hypertension [2]. The maximum deviation in the examined indicators from the physiological norms indicating arterial hypertension was revealed in group 3 with the length of service $>30$ years which may be a result of long-term exposure to unfavorable working conditions.

ADP indicates concurrence in the regulation of the cardiac output and peripheral resistance. The average ADP in the examined group totaled $105 \pm 13.8 \mathrm{mmHg}$. The ADP that was closest to the physiological norm was registered in the group with the length of service 11-20 years. In the groups with the length of service of 20-30 years and over 30 years, the ADP indicator was significantly higher. Lower MBV in the examined groups, except for group 1 with the length of service of 3-10 years, indicates a weaker myocardial contractile function. The mean peripheral vascular resistance in the examined group totaled $2698,2 \pm 1195,6$ dynes. It grows with the length of service and reaches its peak in the group with the length of service $>30$ years $(3077,3 \pm 721,8)$.

The revealed changes in the hemodynamics indicators in the examined operators indicate a desynchronization between the bloodflow regulation meachanisms which may be considered a sign of prepathological changes.

When assessing the integrated microalterations index "Myocard", its zero value was 
estimated according to the heart screening data interpretation procedure as complete absence of any significant deviations from the ideal heart model, value $<15 \%$ indicated that no significant deviations were revealed, from 15 to $19 \%$ - indicated a boundary condition, $>20 \%$ - a possible pathology. The "Myocard" index equal to $100 \%$ corresponded to a pathological complex related to a large degree of deviation in almost all the heart chambers. In the examined group of operators, the mean group value of the indicator did not exceed $15 \%$ meaning that no significant myocardium changes were revealed. However, it is noteworthy that all the examined subgroups had people with boundary conditions.

The results of the IFC study which reflects a potential ability of the body to adapt to the loads, including production activity are presented in Table 3.

Table 3

Adaptation reserves in the bodies of agricultural operators

\begin{tabular}{|c|c|c|c|c|c|}
\hline \multirow{3}{*}{ Indicator } & Entire group & \multicolumn{4}{|c|}{ Length of service in the profession, years } \\
\cline { 2 - 5 } & & $3-10$ & $11-20$ & $21-30$ & $>30$ \\
\cline { 2 - 5 } & $M \pm S D$ & $M \pm S D$ & $M \pm S D$ & $M \pm S D$ & $M \pm S D$ \\
\hline IFC & $2.786 \pm 0.82$ & $2.892 \pm 0,80$ & $2.553 \pm 0.66$ & $\mathbf{2 . 9 3 1} \pm \mathbf{0 . 7 8 *}$ & $\mathbf{3 . 1 4 4} \pm \mathbf{1 . 1 1 *}$ \\
\hline
\end{tabular}

$\mathrm{N}$ ote : *-отмеченные уровни статистически значимо различаются с уровнями группы 2.

The table shows that the mean group IFC (index of functional changes) value in the examined operators totaled $2.786 \pm 0.82$ which fell under the functional strain condition. With longer service, its value changed reaching $3.144 \pm 1.11$ in the group with the length of service of $>30$ years which indicates weaker adaptation abilities in the group and unsatisfactory adaptation to the actual load on the body. At the same time, we revealed statistically significant differences between the IFC levels in the $3^{\text {rd }}$ and $4^{\text {th }}$ groups as compared to group 2 ( $p=0,004182$ and $p=0,000658$ respectively).

\section{Conclusions}

1. During the entire annual production cycle, agricultural operators are exposed to hazardous production and labor factors including uncomfortable heated working environment, working area chemical pollution, noise, vibration, dynamic and static physical loads, and uncomfortable working posture.

2. The level of risk factors falls under hazardous labor conditions of the $1-4^{\text {th }}$ level in terms of deviation from the hygienic standards (classes $3.1-3.4$ ).

3. The arterial blood pressure level, hemodynamics indicators and the index of functional condition (IFC) indicate tension in the regulatory systems and weaker adaptation abilities of the operators which may result from the unfavorable working conditions. 


\section{References}

1. Novikova T.A. Gigienicheskaja ocenka i upravlenie professional'nym riskom dlja zdorov'ja mehanizatorov sel'skogo hozjajstva [Hygienic evaluation and control of occupational health hazards in farm machinery operators]. Zdravoohranenie Rossijskoj Federacii, 2011, no. 11 , pp. 72-73.

2. Baranov V.M., Baevskij R.M., Berseneva A.P., Mihajlov V.M. Ocenka adaptacionnyh vozmozhnostej organizma i zadachi povyshenija jeffektivnosti zdravoohranenija [Evaluation of adaptive abilities of the body and tasks of improving healthcare efficiency]. Jekologija cheloveka, 2004, no. 6, pp. 25-29.

3. Varshamov L.A., Bezrukova G.A., Spirin V.F., Novikova T.A. Professional'naja zabolevaemost' rabotnikov sel'skogo hozjajstva saratovskoj oblasti [Occupational disease of agricultural workers of the Saratov region]. Zdorov'e naselenija i sreda obitanija, 2011, no. 12, pp. 10-13. 